\title{
The Landscape and Therapeutic Implications of Molecular Profiles in Epithelial Ovarian Cancer
}

\author{
Ludivine Dion 1,2,3@ , Isis Carton 1,2, Sylvie Jaillard 2,3,4, Krystel Nyangoh Timoh 1,2, \\ Sébastien Henno ${ }^{5}$, Hugo Sardain ${ }^{1}$, Fabrice Foucher ${ }^{1}$, Jean Levêque ${ }^{1,2}$, \\ Thibault de la Motte Rouge ${ }^{6}$, Susie Brousse ${ }^{1,2}$ (D) and Vincent Lavoué ${ }^{1,2,3, *(D)}$ \\ 1 Service de Chirurgie gynécologique, CHU de Rennes, 35000 Rennes, France; \\ ludivine.dion@chu-rennes.fr (L.D.); isis.carton@hotmail.fr (I.C.); \\ krystel.nyangoh.timoh@chu-rennes.fr (K.N.T.); hugo.sardain@chu-rennes.fr (H.S.); \\ fabrice.foucher@chu-rennes.fr (F.F.); jean.leveque@chu-rennes.fr (J.L.); Susie.brousse@chu-rennes.fr (S.B.) \\ 2 Faculté de médecine, Université de Rennes 1, 35000 Rennes, France; sylvie.jaillard@chu-rennes.fr \\ 3 INSERM U 1085, IRSET, Equipe 8, 35000 Rennes, France \\ 4 Service de Cytogénétique, CHU de Rennes, 35000 Rennes, France \\ 5 Service d'anatomo-pathologie, CHU de Rennes, 35000 Rennes, France; sebastien.henno@chu-rennes.fr \\ 6 Service d'oncologie médicale, CRLCC Eugène Marquis, 35000 Rennes, France; \\ t.delamotterouge@rennes.unicancer.fr \\ * Correspondence: vincent.lavoue@chu-rennes.fr
}

Received: 24 April 2020; Accepted: 10 July 2020; Published: 15 July 2020

\begin{abstract}
Epithelial ovarian cancer (EOC) affects 43,000 women worldwide every year and has a five-year survival rate of $30 \%$. Mainstay treatment is extensive surgery and chemotherapy. Outcomes could be improved by molecular profiling. We conducted a review of the literature to identify relevant publications on molecular and genetic alterations in EOC. Approximately $15 \%$ of all EOCs are due to $B R C A 1$ or $B R C A 2$ mutations. Four histologic subtypes characterized by different mutations have been described: serous, endometrioid, mucinous, and clear-cell. Between $20-30 \%$ of high-grade serous EOCs have a $B R C A$ mutation. Tumors with $B R C A$ mutations are unable to repair double-strand DNA breaks, making them more sensitive to platinum-based chemotherapy and to PolyAdenosine Diphosphate-Ribose Polymerase (PARP) inhibitors. Olaparib is a PARP inhibitor with proven efficacy in $B R C A$-mutated ovarian cancer, but its effectiveness remains to be demonstrated in tumors with a BRCAness (breast cancer) profile (i.e., also including sporadic tumors in patients with deficient DNA repair genes). A universally accepted molecular definition of BRCAness is required to identify optimal theranostic strategies involving PARP inhibitors. Gene expression analyses have led to the identification of four subgroups of high-grade serous EOC: mesenchymal, proliferative, differentiated, and immunoreactive. These subtypes are not mutually exclusive but are correlated with prognosis. They are not yet used in routine clinical practice. A greater understanding of EOC subtypes could improve patient management.
\end{abstract}

Keywords: ovarian cancer; molecular subtypes; BRCA; BRCAness profile; therapeutic approach

\section{Introduction}

Epithelial ovarian cancer (EOC) affects one in every 60 women in industrialized countries [1] and has an annual incidence of approximately 43,000 cases worldwide [2]. It mainly affects women after menopause. The prognosis for ovarian cancer is poor, with a five-year survival rate of just $30 \%$ and most deaths occurring within two years of diagnosis. Approximately $75 \%$ of all women with EOC are diagnosed when the cancer has spread from the ovaries to the entire peritoneal surface (International Federation of Gynecology (FIGO) stages IIIc and IV). The current five-year survival 
rate for patients with FIGO stage IIIc-IV EOC is less than 30\% and no real improvements have been achieved in recent decades [1]. Surgery combined with carboplatin and paclitaxel chemotherapy was the current standard of care prior to the recent development of antiangiogenic agent bevacizumab, which resulted in a modest improvement in progression-free survival (four months) in women with ovarian cancer with a poor prognosis, i.e., women with stages other than FIGO stage IIIc with residual disease after surgery and FIGO stage IV [3]. No significant improvements were observed for overall survival. Olaparib has also provided clear survival benefits in patients with BReast CAncer $(B R C A) 1$ and $B R C A 2$ mutations [4]. A better understanding of the mechanisms underlying treatment failure and the identification of new therapeutic targets are needed in EOC. In this review, we provide an updated overview of the different molecular profiles described for EOC in the literature and discuss their role in the current and future management of this disease.

\section{Materials and Methods}

We performed a literature search of the PubMed database to identify studies relating to molecular and genetic alterations in ovarian cancer in humans. The search was based on the keywords "epithelial ovarian cancer", "mutation", "PolyAdenosine Diphosphate-Ribose Polymerase (PARP) inhibitor", "molecular profiles", and "treatments" and targeted original research articles, case reports, meta-analyses, and reviews published in English between January 2000 and January 2020.

Identification of duplicate studies was facilitated by downloading all the key fields for each study, including unique identifier numbers (e.g., PubMed identifiers (PMIDs) and digital object identifiers (DOIs)), clinical trial numbers, abstracts, and keywords. Titles and abstracts of the studies retrieved were screened for relevance using predefined inclusion and exclusion criteria. Relevant studies were selected for full-text review and data extraction; all other studies were excluded. A search of the gray literature was also conducted to identify unpublished journal articles and conference proceedings, and clinical trial registers were searched for unpublished and ongoing trials. Finally, a hand search was made of the reference lists of selected publications to identify other potentially relevant studies.

\section{Results}

The literature search identified 1079 articles relating to the molecular classification of ovarian cancer; 52 met the inclusion criteria and were included in this review.

\subsection{The Natural History of EOC and Genetic Predisposition}

The natural history of ovarian cancer is marked by a good initial response to standard treatment (surgery and chemotherapy) in $80 \%$ of women. Nonetheless, $70 \%$ of these women will experience disease recurrence, mostly in the form of diffuse peritoneal carcinomatosis, within two years of treatment completion. EOC is classified as platinum-resistant when disease recurs within six months of the end of platinum-based chemotherapy and as platinum-sensitive when it recurs after 12 months of treatment completion, although the period used to define sensitivity varies in the literature [5]. Tumors that recur between these periods are considered to have intermediate sensitivity.

Between $10 \%$ and $15 \%$ of women with EOC are genetically predisposed to ovarian cancer, and $90 \%$ have a $B R C A$ mutation ( $B R C A 1$ or $B R C A 2$ ). The lifetime risk of EOC is $40 \%$ in patients with a $B R C A 1$ mutation versus $15 \%$ in those with a $B R C A 2$ mutation. Hereditary nonpolyposis colorectal cancer (Lynch syndrome) accounts for approximately $10 \%$ of all hereditary EOCs. Less common genetic syndromes, such as Li-Fraumeni syndrome, caused by a P53 mutation, also exist [6-10]. In a study of inherited mutations in women with ovarian cancer, Norquist et al. [11] found that $18.1 \%$ of women had germline mutations in cancer-associated genes. Overall, $14.6 \%$ had mutations in BRCA1 or BRCA2, $3.3 \%$ had mutations in other BRCA-Fanconi anemia genes (BRIP1, PALB2, RAD51C, RAD51D, BARD1), and $0.4 \%$ had mutations in mismatch repair genes linked to Lynch syndrome [10,11]. 


\subsection{Histologic Subtypes of Ovarian Cancer, Molecular Correlates, and Therapeutic Implications}

Four histologic subtypes of EOC have been identified: serous EOC (which is classified as high grade $(71 \%$ of all EOCs) or low grade $(4.1 \%))$, endometrioid EOC $(8.3 \%)$, clear-cell EOC $(9.5 \%)$, and mucinous EOC (3.2\%) [12]. However, observation of histological findings of tubal carcinoma in organs removed prophylactically from women with a genetic predisposition to ovarian cancer [13] led to the establishment of a dualistic classification system that divided EOC into type I (low-grade) carcinoma and type II (high-grade) carcinoma (Table 1).

Table 1. Dualistic classification of EOC.

\begin{tabular}{|c|c|c|}
\hline & Type I EOC & Type II EOC \\
\hline Frequency & $25 \%$ of EOCs & $75 \%$ of EOCs \\
\hline Mortality & $10 \%$ & $90 \%$ \\
\hline Diagnosis & Usually Early stage & $\begin{array}{l}\text { Usually Advanced stage } \\
\text { (carcinomatosis) }\end{array}$ \\
\hline Progression & Slow & Fast \\
\hline Histologic subtypes & $\begin{array}{l}\text { Low-grade serous } \\
\text { Low-grade endometrioid } \\
\text { Clear-cell } \\
\text { Mucinous }\end{array}$ & $\begin{array}{c}\text { High-grade serous } \\
\text { High-grade endometrioid } \\
\text { Undifferentiated carcinoma } \\
\text { Carcinosarcoma }\end{array}$ \\
\hline Mutations & $\begin{array}{c}\text { KRAS, BRAF (serous) } \\
\text { CTTNNB1, PTEN, PI3KCA (endometrioid) } \\
\text { KRAS, BRAF, HER2, P53 (mucinous) } \\
\text { (P53 for 25\% of mucinous EOC) } \\
\text { PI3KCA, HER2 (clear-cell) } \\
\text { ARID1A, PPP2R1A }\end{array}$ & $\begin{array}{c}\text { P53 (96\% of high-grade serous EOCs) } \\
\text { BRCA ( } 21 \% \text { of cases) }\end{array}$ \\
\hline Genomic stability & Stability & Instability \\
\hline Precursors & Benigh cyst » borderline » malignant & Precursors: de novo, STIC \\
\hline
\end{tabular}

Abbreviations: EOC: epithelial ovarian cancer; STIC: serous tubal intraepithelial carcinoma.

Type I EOCs account for $25 \%$ of all EOCs, but cause just $10 \%$ of deaths; they are largely diagnosed at an early stage and have four histologic subtypes characterized by different mutations: (1) low-grade serous EOC (KRAS, BRAF, HER2), (2) endometrioid EOC (PTEN and PI3KCA), (3) mucinous EOC (KRAS), and (4) clear-cell EOC (PI3KCA). They have high genomic stability and span a continuum ranging from a benign cyst to a borderline lesion to an invasive tumor. Type II EOCs are much more common and lethal. They account for $75 \%$ of all EOCs and are responsible for $90 \%$ of deaths. They are typically diagnosed at an advanced stage (carcinomatosis), progress quickly, and include high-grade serous EOC, high-grade endometrioid EOC, carcinosarcoma, and undifferentiated carcinoma. Ninety-six percent of type II EOCs have a P53 mutation, while between $30 \%$ and $50 \%$ have a $B R C A 1$ or $B R C A 2$ mutation (the percentage varies depending on the application of BRCA or BRCAness criteria) [14]. The concept of 'BRCAness' defines the pathogenesis and vulnerability of multiple cancers. The canonical definition of BRCAness is a defect in homologous recombination repair, mimicking BRCA1 or BRCA2 loss. In turn, BRCA-deficient cells utilize error-prone DNA repair pathways, causing increased genomic instability, which may be responsible for their sensitivity to DNA damaging agents and poly(ADPribose) polymerase (PARP) inhibitors. Other defects in homologous recombination repair genes, such as EMSY, RAD51, ATM, ATR, Fanconi anemia, BARD1, BRIP1, $P A L B 2, R B 1, N F 1, C D K N 2 A$, and the suppression of BRCA1 transcriptional activation through gene methylation, are associated with homologous recombination deficiency (HRD) $[15,16]$. The finding that HRD contributes to approximately $50 \%$ of type II EOC provided a rationale for using cytotoxic platinum-based chemotherapy and exploring the activity of PARP inhibitors in type II EOC. It has been demonstrated that PARP inhibitors are active in high grade serous EOC beyond those with BRCA mutations [17]. 
Type II EOCs have high genomic instability. Their precursor lesions are serous tubal intraepithelial carcinomas which are identical in appearance to high-grade serous papillary carcinomas and have the same P53 mutations [13]. Other pathways in type II EOCs involved the overexpression of CCNE1, a gene encoding cell cycle protein cyclin E1, which leads to unscheduled DNA replication, centrosome amplification, and overall chromosomal instability [16] and also FXM1, which is altered in nearly $84 \%$ of high grade serous EOC, followed by Rb1 (67\%), phosphatidylinositol-4,5-biphosphate 3-kinase (PI3K) (45\%), and Notch 1 (22\%) pathways, all of which could lead to novel therapeutic opportunities for patients with high grade serous EOC [10].

Although the dualistic classification of EOC into "type I" and "type II" is widely applied in research presentations and manuscripts, it is often used as a convenient way of conceptualizing different mechanisms of tumorigenesis amongst EOC. This classic dualistic classification conflicts with some recent molecular studies as not all type I EOCs are not homogenous, even within the histological types, and a proportion can have poor clinical outcomes such as high grade mucinous features because of the high rate of proliferation and advanced stage diagnosis (Table 2). Indeed, the impression that only type II carcinomas are aggressive, have poor prognosis, and carry TP53 mutations is not realistic. Although type II serous and type I low grade serous carcinomas best fit the description of the dualistic model, with different precursors and very distinct pathology and molecular profiles, there are very clear differences between mucinous ovarian carcinomas and other type I tumors. These include an unknown cell of origin and a very heterogeneous mutation profile (including TP53 mutant cases) and clinical behavior, indicating a non-type I classification for this entity. Thus, a greater understanding of the genomic mutations associated with the different histologic subtypes of EOC could help identify targeted systemic treatments.

Table 2. EOC classified according Histologic Subtype.

\begin{tabular}{|c|c|c|c|c|c|}
\hline Histologic Subtype & High-Grade Serous & $\begin{array}{l}\text { Low-Grade } \\
\text { Serous }\end{array}$ & Mucinous & Endometrioid & Clear-Cell \\
\hline $\begin{array}{c}\% \text { of all } \\
\text { EOCs diagnosed }\end{array}$ & $71 \%$ & $4 \%$ & $3 \%$ & $8 \%$ & $9 \%$ \\
\hline $\begin{array}{l}\% \text { of early stage } \\
\text { EOCs diagnosed }\end{array}$ & Nearly $0 \%$ & $17 \%$ & $12 \%$ & $33 \%$ & $38 \%$ \\
\hline $\begin{array}{l}\% \text { of advanced stage } \\
\text { EOCs diagnosed }\end{array}$ & $88 \%$ & $3 \%$ & $2 \%$ & $3 \%$ & $4 \%$ \\
\hline Progression speed & High & low & $\begin{array}{l}\text { low }(50 \%) \\
\text { high }(50 \%)\end{array}$ & $\begin{array}{l}\text { Low }(90 \%) \\
\text { High }(10 \%)\end{array}$ & low \\
\hline Mutations & $\begin{array}{c}\text { P53 } \\
\text { BRCA1 or BRCA2 }\end{array}$ & $\begin{array}{l}\text { KRAS } \\
\text { BRAS } \\
\text { HER2 }\end{array}$ & $\begin{array}{c}\text { P53 } \\
\text { KRAS }\end{array}$ & $\begin{array}{c}\text { PTEN } \\
\text { PI3KCA }\end{array}$ & PI3KCA \\
\hline $\begin{array}{l}\text { Intracellular signaling } \\
\text { pathway targeted }\end{array}$ & $\begin{array}{l}\text { P53, which controls } \\
\text { mitosis and apoptosis }\end{array}$ & \multicolumn{2}{|c|}{$\begin{array}{c}\text { MEK/BRAF/KRAS } \\
\text { pathway }\end{array}$} & \multicolumn{2}{|l|}{ PI3K/AKT/mTor } \\
\hline $\begin{array}{c}\text { Function of } \\
\text { signaling pathway }\end{array}$ & $\begin{array}{c}\text { BRCA involved in } \\
\text { double-strand DNA repair }\end{array}$ & \multicolumn{2}{|c|}{ Cell proliferation } & $\begin{array}{l}\text { Regulates cell } \\
\text { proliferation, motility, } \\
\text { and survival }\end{array}$ & \\
\hline $\begin{array}{l}\text { Drugs targeting } \\
\text { signaling pathway }\end{array}$ & $\begin{array}{l}\text { PARP inhibitor (olaparib) } \\
\text { for tumors with a } \\
\text { BRCAness profile }\end{array}$ & \multicolumn{2}{|c|}{$\begin{array}{l}\text { Selumetinib, trametinib, } \\
\text { dabrafenib }\end{array}$} & $\begin{array}{l}\text { mTor inhibitor } \\
\text { (e.g., temsirolimus, } \\
\text { everolimus) }\end{array}$ & \\
\hline
\end{tabular}

Abbreviations: EOC: epithelial ovarian cancer; BRCA: Breast Cancer; PARP: Poly Adenosine Diphosphate-Ribose Polymerase; MEK: mitogen-activated protein kinase kinase enzymes; BRAF: B-Raf protein; KRAS: K-ras Oncogene; PI3K: phosphatidylinositol-4,5-biphosphate 3-kinase; AKT: Activation Of The Serine/Threonine-specific Protein Kinase; mTor: Mammalian Target Of Rapamycin; P53: Protein 53.

Low-grade serous ovarian cancer represents about $10 \%$ of EOCs [18]. It is hypothesized that low-grade serous ovarian cancer develops from an atypical, proliferative (borderline) tumor [18]. Mutations in BRAF (38\%) or KRAS (19\%) are the most common aberrations detected in low grade serous EOC [19]. Although they are associated with a constitutively active Mitogen-Activated Protein 
Kinase (MAPK) pathway, mutations in BRAF or KRAS represent a favorable prognostic factor [18]. An activated MAPK pathway is detected in up to $80 \%$ of low-grade serous ovarian cancers and in $78 \%$ of their putative precursors (serous borderline tumors), suggesting a causative effect $[10,20]$. This point also provides a rationale for exploring MAPK kinase (MEK) inhibitors in the treatment of low-grade serous ovarian cancer, such as selumetinib, trametinib or dabrafenib, which are MEK1 and MEK2 inhibitors (MEKi) that indirectly inhibit the BRAF and KRAS pathways [21]. However, the MEKi selumetinib has shown little activity in patients with low-grade serous cancers $(15 \%)$, where the response did not always correlate with KRAS/BRAF mutation status [22]. With another MEKi, clinical response to the BRAF inhibitor, dabrafenib, has been demonstrated thus far clinically in $20 \%$ women with BRAF V600E mutated low-grade carcinomas [23].

Clear-cell ovarian cancers display mutations in the SWItch/Sucrose Non-Fermentable (SWI/SNF) chromatin-remodeling complex genes, the PI3K/Akt signaling pathway, and the receptor tyrosine kinase (RTK)/Ras signaling pathway in nearly $50 \%, 40 \%$, and $29 \%$ of clear-cell ovarian cancers, respectively $[10,24,25]$. Among the SWI/SNF subunits, ARID1A is the most frequently mutated gene, detected in $40 \%$ to $67 \%$ of clear-cell ovarian cancers [26,27]. In the PI3K signaling pathway, activating mutations in PIK3 catalytic subunit $\alpha$ (PIK3CA) (33\%) and loss of phosphatase and tensin homolog (PTEN) (37\%) are the most common mutations [26,28]. Thus, women with low-grade clear-cell EOC could benefit from treatment with mTor inhibitors targeting the PI3K/AKT/mTor pathway [21]. A good amount of research was also done in terms of targeted therapy for AT-rich Interactive Domain 1A (ARID1A) mutated clear-cell carcinoma, such as ENMD-2076 [29]. In the same way, small molecule inhibitors of the bromodomain and extra terminal domain (BET) family of proteins specifically inhibit proliferation of ARID1A mutated cell lines, both in vitro and in ovarian clear-cell cancer xenografts and patient-derived xenograft models. BET inhibitors cause a reduction in the expression of multiple SWI/SNF members including ARID1B, providing a potential explanation for the observed lethal interaction with ARID1A loss [30].

Endometrioid ovarian cancers and clear-cell ovarian cancers arise from similar precursor cells of transformed endometrial origin. Women with Lynch syndrome are also at an increased risk of developing endometrioid and clear-cell ovarian cancer. Loss of expression of mismatch repair genes (a characteristic of Lynch syndrome) is found in nearly $8 \%$ of Lynch syndrome-associated endometrioid and clear-cell ovarian cancers [31]. Molecular profiling of human endometrioid ovarian cancers revealed that the most prevalent mutations are similar to those observed in clear-cell ovarian cancer and include PIK3CA (40\%), ARID1A (30\%), KRAS (30\%), PTEN (16\%), and PPP2R1A (16\%) [32,33]. Interestingly, mutations in CTNNB1 are particularly common, occurring in approximately $50 \%$ of low-grade endometrioid ovarian cancers [32,34]. High-grade endometrioid is a different entity than low-grade endometrioid and shares similarities with high grade serous EOC.

Mucinous ovarian carcinoma responds poorly to conventional chemotherapy regimens. Although long overall survival outcomes can occur with early detection and optimal surgical resection, recurrent and advanced disease are associated with extremely poor survival. Molecular aberrations noted in mucinous ovarian cancer that suggest a match with current targeted therapies include amplification of ERBB2 (26.7\%) and BRAF mutation (9\%). Observed genetic events that suggest potential efficacy for agents currently in clinical trials include: KRAS/NRAS mutation (66\%), TP53 missense mutation (49\%), RNF43 mutation (11\%), ARID1A mutation (10\%), and PIK3CA/PTEN mutation $(9 \%)$. Therapies exploiting homologous recombination deficiency (see below) may not be effective in mucinous ovarian cancer, as only one out of 191 had a high homologous recombination deficiency score $[23,35]$.

Nevertheless, it is not easy to evaluate the effectiveness of these new targeted therapies in the different histologic and molecular subtypes of EOC. Type 1 EOCs, for instance, which account for just $25 \%$ of all EOCs, are mostly diagnosed at an early stage when they are limited to the ovaries and can be treated surgically without the need for adjuvant therapy. Just 10\% are diagnosed at a more advanced stage (carcinomatosis or lymph node involvement), which is when they need treatment with 
adjuvant systemic therapy. The scarcity of advanced cases thus makes it very difficult, if not impossible, to form a sufficiently large cohort to analyze the effectiveness of targeted treatments. That said, a number of trials have been conducted, but many of them are inconclusive because of lack of inclusion. For example, the phase III MILO trial (NCT01849874), designed to evaluate the efficacy of the MEK inhibitor binimetinib in low-grade serous EOCs, had to be stopped prematurely due to a lack of efficacy. Thus, drugs targeting signaling pathways need to be mindful that many of the trials have closed with poor results, suggesting that a dualistic approach to treatment is likely that way forward, particularly for mucinous cancers.

\subsection{BRCAness: Definition and Treatment Implications}

Between $30 \%$ and $40 \%$ of patients with type II EOC have a BRCA mutation. The $B R C A 1$ gene is located on chromosome 17. BRCA1 mutations are of germline or somatic origin in $11.5 \%$ of cases and of epigenetic origin (inactivation due to gene promoter methylation) in $10.5 \%$. The BRCA2 gene is located on chromosome 14 and $9.2 \%$ of patients have germline or somatic mutations [36]. BRCA mutant carriers have a better prognosis than wild-type carriers or patients with epigenetic silencing [12]. BRCA genes are involved in DNA double-strand break repair by homologous recombination. When DNA damage occurs (induced, for example, by platinum-based chemotherapy), there are two possible repair pathways: the homologous recombination double-strand DNA repair pathway and the alternative single-strand break repair pathway, which involves a group of non-homologous end joining (NHEJ) genes and single-strand annealing (SSA) genes that use several enzymes, including PARP (Figure 1). In the absence of double-strand break repair due to, for example, deficient $B R C A 1$ or $B R C A 2$ function, the default single-strand repair pathway is engaged, but this results in genomic instability in the reading frame and genomic mutations. This instability would explain the higher prevalence of EOC in patients with $B R C A 1$ or $B R C A 2$ mutations, as there would be an accumulation of cell clones harboring activating mutations in oncogenes or inhibiting mutations in tumor suppressor genes. Defective DNA repair at the tumor level exists in EOC, as $30 \%$ to $40 \%$ of patients have a non-functional $B R C A$ gene. This deficiency probably explains the better prognosis observed in carriers of $B R C A$ mutations when their tumor is subjected to selective pressure imposed by platinum-based chemotherapy, as the single-strand repair capacity would probably be exceeded. Accumulation of unrepaired DNA damage results in cell apoptosis once a certain threshold is passed. PARP inhibitors such as olaparib can be used to exploit double-strand DNA repair deficiencies by inhibiting the single-strand DNA repair pathway and preventing DNA repair in patients treated with platinum-based chemotherapy. In the presence of cumulative unrepaired DNA damage, the tumor cells would enter apoptosis. This process is known as synthetic lethality. Synthetic lethality induced by PARP inhibitors has been found to result in a significant clinical benefit in patients with ovarian cancer. Specifically, carriers of constitutional (inherited) or somatic (acquired) BRCA mutations achieved a significant gain of seven months disease-free survival in patients treated with olaparib maintenance therapy for at least nine months [37]. A number of questions, however, remain in relation to the use of PARP inhibitors. First, would PARP inhibitors benefit patients who lack $B R C A$ expression due to epigenetic inactivation through DNA methylation? Second, would all EOC patients with a BRCAness profile benefit from PARP inhibitors, i.e., patients with a mutation in any of the proteins responsible for double-strand DNA repair (homologous recombination) whether that be BRCA or BRIP2, CHEK2, RAD51c, or PTEN $[38,39]$ ? Third, can the somatic characterization of the BRCAness profile be simplified in order to offer theranostic options to patients other than those with congenital BRCA mutations? Although the definition of BRCAness varies from one series to the next, molecular profiling of high-grade serous EOCs has shown that $30 \%$ to $60 \%$ of patients have deficiencies in homologous recombination or other DNA repair pathways $[14,38,40]$. A number of studies have attempted to identify molecular signatures that would provide a simple, reproducible method for predicting BRCAness profiles based on genomic instability [41,42]. Similar studies have been conducted in the field of breast cancer, particularly triple-negative breast cancer $[43,44]$. The difficulty with these studies is the lack of consensus on the 
molecular definition of BRCAness. The strategy proposed for overcoming this difficulty in therapeutic trials is to use PARP inhibitors for patients who respond well to platinum-based drugs and therefore theoretically have defective double-strand DNA repair. Two examples are the phase II ARIEL3 trial with rucaparib and the NOVA trial with niraparib. The NOVA trial showed that niraparib was effective in patients with platinum-sensitive ovarian cancer, demonstrating that PARP inhibitors are effective in carriers of mutations other than BRCA1 and BRCA2 [24]. Efforts are also underway to analyze the combined use of drugs with different effects. Researchers in the PAOLA trial, for example, recently showed that the combined use of PARP inhibitors and antiangiogenic agents as first-line maintenance therapy for patients with ovarian cancer is superior to bevacizumab alone $[45,46]$.
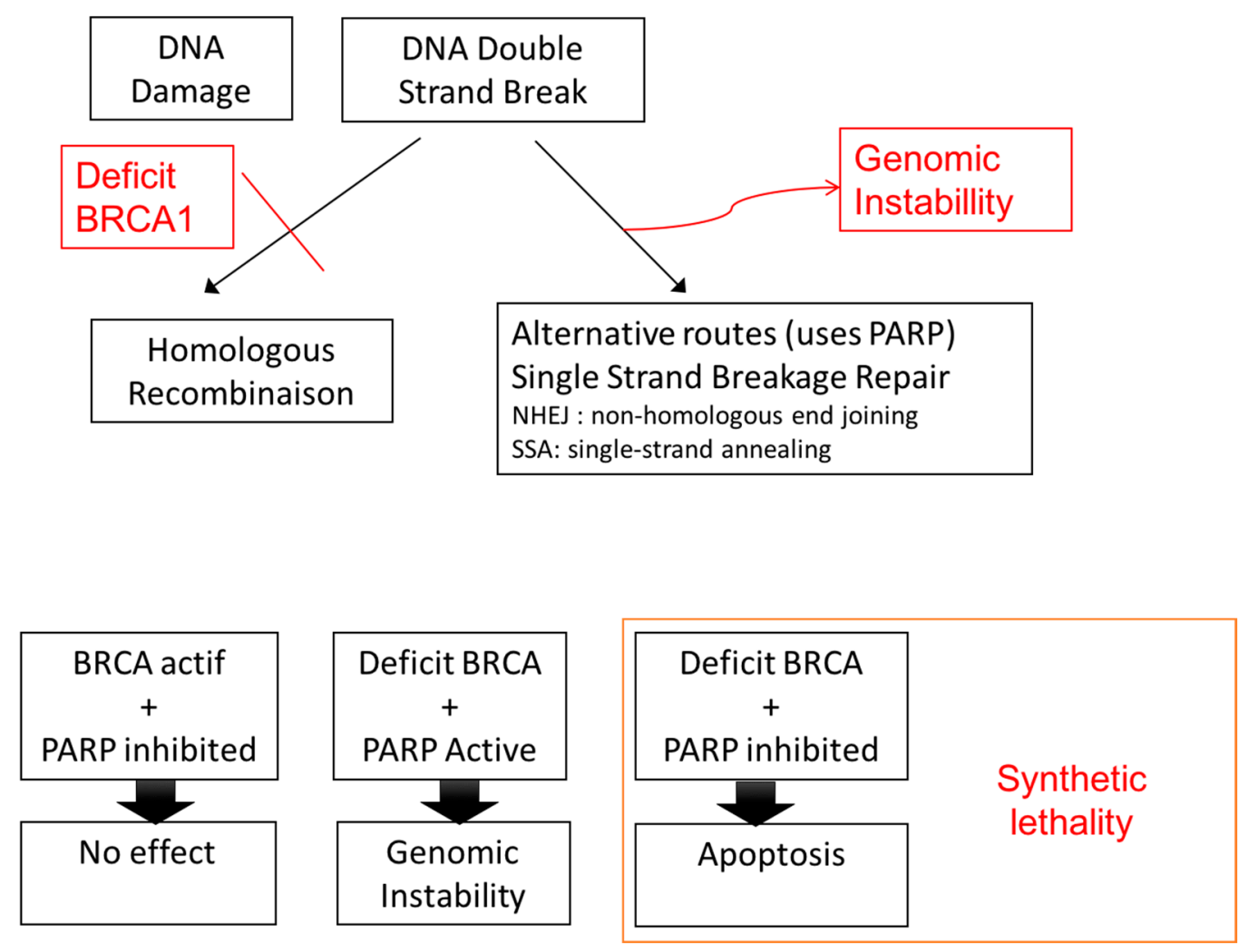

Figure 1. Concept of synthetic lethality. PARP: Poly Adenosine Diphosphate-Ribose Polymerase; BRCA: Breast Cancer.

\subsection{Four Subtypes of Serous Papillary EOC: Diagnostic and Therapeutic Implications}

Large-scale molecular characterization of several hundred high-grade serous ovarian cancers from the Cancer Genome Atlas Research Network led to the identification of four molecular subtypes of ovarian cancer (Table 3): (1) a mesenchymal subtype with gene expression in the stromal component (e.g., fibroblasts, vascular pericytes), (2) a proliferative subtype with high expression of transcription factors and proliferation markers, (3) a differentiated subtype with expression of differentiation markers, and (4) an immunoreactive subtype with high expression of T-cell chemokine ligands, major histocompatibility complex I and II genes, and PD-L1 (programmed cell death ligand 1) genes (Table 2) [14]. This gene expression-based signature was created using 1500 genes and then simplified to create a prognostic "Classification of Ovarian Cancer" (CLOVAR) model based on 100 genes [47]. According to the CLOVAR signature, the mesenchymal subtype (19\% of cases) is associated with the least favorable prognosis, with a five-year survival rate of just $18 \%$. This is followed by the proliferative subtype ( $25 \%$ of cases) with a five-year survival of $22 \%$, the differentiated subtype ( $25 \%$ of cases) with a five-year survival of $40 \%$, and the immunoreactive subtype with a five-year survival of $42 \%$ [40]. The CLOVAR model can be used to distinguish between different types 
of high-grade serous papillary ovarian cancers and could have important theranostic implications. In fact, a retrospective analysis of data from the ICON7 clinical trial showed that bevacizumab provided a survival benefit bordering on significance $(p=0.053)$ in patients with the mesenchymal subtype of serous ovarian cancer; the survival gain observed for the other subtypes was clearly non-significant [48]. Likewise, patients with the immunoreactive subtype, characterized by high expression of Programmed Death-ligand 1 (PD-L1), could potentially benefit from anti-PD1 and anti-PD-L1 monoclonal antibodies. These new immunotherapy drugs can reverse tumor-mediated immunosuppression, providing a survival advantage that has already been observed in melanoma and lung cancer [49]. In ovarian cancer, phase II [50] and ongoing phase III trials have also reported very encouraging results. PD1 and PD-L1 inhibitors may also be an option for maintenance therapy, although numerous issues remain to be investigated, such as societal costs and treatment duration. The prognostic CLOVAR signature is still at the research stage but could have valuable applications in clinical practice in the future. One of the shortcomings of this model is that high-grade serous papillary EOC subtypes are not mutually exclusive, with one study showing that $40 \%$ of cancers could be assigned to two subtypes [40]. Breast cancer is different in this respect, as subtypes such as luminal A, luminal B, and triple-negative breast cancer are mutually exclusive. This mutual exclusion enables a clear classification system that is very useful for stratifying systemic treatments.

Table 3. Four subtypes of high-grade serious ovarian cancer according to expression profile.

\begin{tabular}{ccccc}
\hline $\begin{array}{c}\text { Subtypes of High-Grade } \\
\text { Serous Ovarian Cancer }\end{array}$ & High Expression & Low Expression & $\begin{array}{c}\text { Five-Year } \\
\text { Survival }\end{array}$ & $\begin{array}{c}\text { Potential Targeted } \\
\text { Therapy }\end{array}$ \\
\hline Mesenchymal & $\begin{array}{c}\text { Genes in stromal } \\
\text { component (fibroblasts, } \\
\text { vascular pericytes, etc.) }\end{array}$ & $18 \%$ & $\begin{array}{c}\text { Bevacizumab } \\
\text { (anti-VEGF) }\end{array}$ \\
\hline Proliferative & $\begin{array}{c}\text { Transcription factors and } \\
\text { proliferation markers }\end{array}$ & $\begin{array}{c}\text { Differentiation markers } \\
\text { (MUC16 and MUC1) }\end{array}$ & $22 \%$ & $\begin{array}{c}\text { Bevacizumab } \\
\text { (anti-VEGF) }\end{array}$ \\
\hline Differentiated & $\begin{array}{c}\text { Differentiation markers } \\
\text { (MUC16 and MUC1) }\end{array}$ & $42 \%$ & \\
\hline Immunoreactive & $\begin{array}{c}\text { T-cell chemokines } \\
\text { MHC class I and II } \\
\text { PD-L1 }\end{array}$ & $45 \%$ & $\begin{array}{c}\text { Nivolumab } \\
\text { (Anti PD1/PD-L1 } \\
\text { monoclonal antibody) }\end{array}$ \\
\hline
\end{tabular}

Abbreviations: MHC: major histocompatibility complex; PD-L1: programmed cell death ligand 1; MUC: Mucin; VEGF: Vascular Endothelial Growth Factor.

In another way, compared with high grade serous ovarian cancer, most clear-cell ovarian cancers are characterized by considerably fewer copy number alterations, and mutations in TP53 and BRCA1/BRCA2 genes are uncommon [51]. However, recently, a pilot study highlighted a unique subset of clear-cell ovarian cancer that have microsatellite instability associated with enhanced immunogenicity, which may be susceptible to immunotherapy. This subgroup of clear-cell ovarian cancer exhibited a significantly higher number of tumor-infiltrating lymphocytes (TILs), particularly programmed cell death protein 1 (PD-1)-positive TILs, compared with microsatellite-stable clear-cell ovarian cancer as well as high grade serous ovarian cancer, and uniformly expressed programmed death-ligand 1 (PD-L1) in tumor cells and/or intraepithelial or peritumoral immune cells [52]. Thus, this clear-cell ovarian cancer subtype could potentially benefit from anti-PD1 and anti-PD-L1 monoclonal antibodies.

\section{Conclusions}

EOC is an aggressive cancer and type II EOC has a particularly poor prognosis (overall five-year survival rate $<20 \%$ ) as it is normally diagnosed at an advanced stage when peritoneal carcinomatosis has already occurred. Molecular characterization of EOC has already led to the identification of extremely interesting treatments, such as PARP inhibitors for patients with a BRCAness profile and immunotherapy drugs capable of reverting tumor-induced immunosuppression. These new drugs offer hope in a field that has seen no significant improvements in survival for several decades. Much work, 
however, remains to improve the molecular characterization of EOC and pave the way for targeted therapies and long-awaited personalized medicine for women with ovarian cancer. Finally, the use of PARP inhibitors, PD1/PD-L1 inhibitors, and antiangiogenic drugs such as bevacizumab as maintenance therapy is likely to change current treatment paradigms. The goal of the current standard of care-surgery and systemic chemotherapy—is to eliminate or reduce tumor burden to a minimum, but the extent of residual disease varies and maintenance therapy could offer a means of controlling this "ever-present" disease. The definitions of platinum-sensitive and -resistant EOC based on time of disease recurrence (before or after six months of the end of chemotherapy) that currently determine the need for platinum retreatment will probably evolve as new treatments result in longer disease-free periods. Similarly, the concept of late recurrence (i.e., at least 18 months disease free), which could be addressed by new surgery if localized, will probably need to be reviewed. Finally, the increasing use of maintenance treatments capable of slowing disease progression will probably mean that the current surgical dogma of achieving zero residual disease will probably no longer apply in a few decades.

Author Contributions: Conceptualization, L.D., I.C. and V.L.; methodology, L.D., S.J., K.N.T. and V.L.; software, T.d.I.M.R. and F.F.; validation, J.L., H.S., S.B. and V.L.; formal analysis, L.D.; investigation, V.L. and L.D.; resources, S.H. and S.B..; data curation, S.J. and K.N.T.; writing—original draft preparation, V.L.; writing—review and editing, L.D. and V.L.; visualization, J.L.; supervision, J.L. and V.L.; project administration, V.L. All authors have read and agreed to the published version of the manuscript.

Funding: This research received no external funding

Acknowledgments: Authors thanks Felicity Neilson for editing manuscript.

Conflicts of Interest: The authors declare no conflict of interest.

\section{References}

1. Jayson, G.C.; Kohn, E.C.; Kitchener, H.C.; Ledermann, J.A. Ovarian cancer. Lancet 2014, 384, $1376-1388$. [CrossRef]

2. Jemal, A.; Bray, F.; Center, M.M.; Ferlay, J.; Ward, E.; Forman, D. Global cancer statistics. CA Cancer J. Clin. 2011, 61, 69-90. [CrossRef] [PubMed]

3. Perren, T.J.; Swart, A.M.; Pfisterer, J.; Ledermann, J.A.; Pujade-Lauraine, E.; Kristensen, G.; Carey, M.S.; Beale, P.; Cervantes, A.; Kurzeder, C.; et al. A phase 3 trial of bevacizumab in ovarian cancer. N. Engl. J. Med. 2011, 365, 2484-2496. [CrossRef] [PubMed]

4. Moore, K.; Colombo, N.; Scambia, G.; Kim, B.G.; Oaknin, A.; Friedlander, M.; Lisyanskaya, A.; Floquet, A.; Leary, A.; Sonke, G.S.; et al. Maintenance Olaparib in Patients with Newly Diagnosed Advanced Ovarian Cancer. N. Engl. J. Med. 2018, 379, 2495-2505. [CrossRef]

5. Naumann, R.W.; Coleman, R.L. Management strategies for recurrent platinum-resistant ovarian cancer. Drugs 2011, 71, 1397-1412. [CrossRef]

6. Risch, H.A.; McLaughlin, J.R.; Cole, D.E.; Rosen, B.; Bradley, L.; Fan, I.; Tang, J.; Li, S.; Zhang, S.; Shaw, P.A.; et al. Population BRCA1 and BRCA2 mutation frequencies and cancer penetrances: A kin-cohort study in Ontario, Canada. J. Natl. Cancer Inst. 2006, 98, 1694-1706. [CrossRef]

7. Chen, S.; Iversen, E.S.; Friebel, T.; Finkelstein, D.; Weber, B.L.; Eisen, A.; Peterson, L.E.; Schildkraut, J.M.; Isaacs, C.; Peshkin, B.N.; et al. Characterization of BRCA1 and BRCA2 mutations in a large United States sample. J. Clin. Oncol. 2006, 24, 863-871. [CrossRef]

8. Hennessy, B.T.; Coleman, R.L.; Markman, M. Ovarian cancer. Lancet 2009, 374, 1371-1382. [CrossRef]

9. Lynch, H.T.; Casey, M.J.; Snyder, C.L.; Bewtra, C.; Lynch, J.F.; Butts, M.; Godwin, A.K. Hereditary ovarian carcinoma: Heterogeneity, molecular genetics, pathology, and management. Mol. Oncol. 2009, 3, 97-137. [CrossRef]

10. Lheureux, S.; Braunstein, M.; Oza, A.M. Epithelial ovarian cancer: Evolution of management in the era of precision medicine. CA Cancer J. Clin. 2019, 69, 280-304. [CrossRef]

11. Norquist, B.M.; Harrell, M.I.; Brady, M.F.; Walsh, T.; Lee, M.K.; Gulsuner, S.; Bernards, S.S.; Casadei, S.; Yi, Q.; Burger, R.A.; et al. Inherited Mutations in Women With Ovarian Carcinoma. JAMA Oncol. 2016, 2, 482-490. [CrossRef] [PubMed] 
12. Bashashati, A.; Ha, G.; Tone, A.; Ding, J.; Prentice, L.M.; Roth, A.; Rosner, J.; Shumansky, K.; Kalloger, S.; Senz, J.; et al. Distinct evolutionary trajectories of primary high-grade serous ovarian cancers revealed through spatial mutational profiling. J. Pathol. 2013, 231, 21-34. [CrossRef] [PubMed]

13. Kurman, R.J.; Shih Ie, M. Molecular pathogenesis and extraovarian origin of epithelial ovarian cancer-shifting the paradigm. Hum. Pathol. 2011, 42, 918-931. [CrossRef] [PubMed]

14. Cancer Genome Atlas Research, N. Integrated genomic analyses of ovarian carcinoma. Nature 2011, 474, 609-615. [CrossRef]

15. Bowtell, D.D.; Bohm, S.; Ahmed, A.A.; Aspuria, P.J.; Bast, R.C., Jr.; Beral, V.; Berek, J.S.; Birrer, M.J.; Blagden, S.; Bookman, M.A.; et al. Rethinking ovarian cancer II: Reducing mortality from high-grade serous ovarian cancer. Nat. Rev. Cancer. 2015, 15, 668-679. [CrossRef]

16. Kroeger, P.T., Jr.; Drapkin, R. Pathogenesis and heterogeneity of ovarian cancer. Curr. Opin. Obstet. Gynecol. 2017, 29, 26-34. [CrossRef]

17. Gelmon, K.A.; Tischkowitz, M.; Mackay, H.; Swenerton, K.; Robidoux, A.; Tonkin, K.; Hirte, H.; Huntsman, D.; Clemons, M.; Gilks, B.; et al. Olaparib in patients with recurrent high-grade serous or poorly differentiated ovarian carcinoma or triple-negative breast cancer: A phase 2, multicentre, open-label, non-randomised study. Lancet Oncol. 2011, 12, 852-861. [CrossRef]

18. Kaldawy, A.; Segev, Y.; Lavie, O.; Auslender, R.; Sopik, V.; Narod, S.A. Low-grade serous ovarian cancer: A review. Gynecol. Oncol. 2016, 143, 433-438. [CrossRef]

19. Jones, S.; Wang, T.L.; Kurman, R.J.; Nakayama, K.; Velculescu, V.E.; Vogelstein, B.; Kinzler, K.W.; Papadopoulos, N.; Shih Ie, M. Low-grade serous carcinomas of the ovary contain very few point mutations. J. Pathol. 2012, 226, 413-420. [CrossRef]

20. Hsu, C.Y.; Bristow, R.; Cha, M.S.; Wang, B.G.; Ho, C.L.; Kurman, R.J.; Wang, T.L.; Shih Ie, M. Characterization of active mitogen-activated protein kinase in ovarian serous carcinomas. Clin. Cancer. Res. 2004, 10, 6432-6436. [CrossRef]

21. Banerjee, S.; Kaye, S.B. New strategies in the treatment of ovarian cancer: Current clinical perspectives and future potential. Clin. Cancer. Res. 2013, 19, 961-968. [CrossRef]

22. Farley, J.; Brady, W.E.; Vathipadiekal, V.; Lankes, H.A.; Coleman, R.; Morgan, M.A.; Mannel, R.; Yamada, S.D.; Mutch, D.; Rodgers, W.H.; et al. Selumetinib in women with recurrent low-grade serous carcinoma of the ovary or peritoneum: An open-label, single-arm, Phase 2 study. Lancet Oncol. 2013, 14, 134-140. [CrossRef]

23. Pauly, N.; Ehmann, S.; Ricciardi, E.; Ataseven, B.; Bommert, M.; Heitz, F.; Prader, S.; Schneider, S.; Du Bois, A.; Harter, P.; et al. Low-grade serous tumors: Are we making progress? Curr. Oncol. Rep. 2020, 22, 8. [CrossRef] [PubMed]

24. Marks, E.I.; Brown, V.S.; Dizon, D.S. Genomic and Molecular Abnormalities in Gynecologic Clear Cell Carcinoma. Am. J. Clin. Oncol. 2020, 43, 139-145. [CrossRef] [PubMed]

25. Fukumoto, T.; Magno, E.; Zhang, R. SWI/SNF Complexes in Ovarian Cancer: Mechanistic Insights and Therapeutic Implications. Mol. Cancer. Res. 2018, 16, 1819-1825. [CrossRef] [PubMed]

26. Itamochi, H.; Oishi, T.; Oumi, N.; Takeuchi, S.; Yoshihara, K.; Mikami, M.; Yaegashi, N.; Terao, Y.; Takehara, K.; Ushijima, K.; et al. Whole-genome sequencing revealed novel prognostic biomarkers and promising targets for therapy of ovarian clear cell carcinoma. Br. J. Cancer 2017, 117, 717-724. [CrossRef]

27. Shibuya, Y.; Tokunaga, H.; Saito, S.; Shimokawa, K.; Katsuoka, F.; Bin, L.; Kojima, K.; Nagasaki, M.; Yamamoto, M.; Yaegashi, N.; et al. Identification of somatic genetic alterations in ovarian clear cell carcinoma with next generation sequencing. Genes Chromosomes Cancer 2018, 57, 51-60. [CrossRef]

28. Hashiguchi, Y.; Tsuda, H.; Inoue, T.; Berkowitz, R.S.; Mok, S.C. PTEN expression in clear cell adenocarcinoma of the ovary. Gynecol. Oncol. 2006, 101, 71-75. [CrossRef]

29. Lheureux, S.; Tinker, A.; Clarke, B.; Ghatage, P.; Welch, S.; Weberpals, J.I.; Dhani, N.C.; Butler, M.O.; Tonkin, K.; Tan, Q.; et al. A Clinical and Molecular Phase II Trial of Oral ENMD-2076 in Ovarian Clear Cell Carcinoma (OCCC): A Study of the Princess Margaret Phase II Consortium. Clin. Cancer. Res. 2018, 24, 6168-6174. [CrossRef]

30. Berns, K.; Caumanns, J.J.; Hijmans, E.M.; Gennissen, A.M.C.; Severson, T.M.; Evers, B.; Wisman, G.B.A.; Jan Meersma, G.; Lieftink, C.; Beijersbergen, R.L.; et al. ARID1A mutation sensitizes most ovarian clear cell carcinomas to BET inhibitors. Oncogene 2018, 37, 4611-4625. [CrossRef] 
31. Vierkoetter, K.R.; Ayabe, A.R.; VanDrunen, M.; Ahn, H.J.; Shimizu, D.M.; Terada, K.Y. Lynch Syndrome in patients with clear cell and endometrioid cancers of the ovary. Gynecol. Oncol. 2014, 135, 81-84. [CrossRef] [PubMed]

32. McConechy, M.K.; Ding, J.; Senz, J.; Yang, W.; Melnyk, N.; Tone, A.A.; Prentice, L.M.; Wiegand, K.C.; McAlpine, J.N.; Shah, S.P.; et al. Ovarian and endometrial endometrioid carcinomas have distinct CTNNB1 and PTEN mutation profiles. Mod. Pathol. 2014, 27, 128-134. [CrossRef] [PubMed]

33. Cybulska, P.; Paula, A.D.C.; Tseng, J.; Leitao, M.M., Jr.; Bashashati, A.; Huntsman, D.G.; Nazeran, T.M.; Aghajanian, C.; Abu-Rustum, N.R.; DeLair, D.F.; et al. Molecular profiling and molecular classification of endometrioid ovarian carcinomas. Gynecol. Oncol. 2019, 154, 516-523. [CrossRef] [PubMed]

34. Nakayama, K.; Rahman, M.T.; Rahman, M.; Nakamura, K.; Ishikawa, M.; Katagiri, H.; Sato, E.; Ishibashi, T.; Iida, K.; Ishikawa, N.; et al. CCNE1 amplification is associated with aggressive potential in endometrioid endometrial carcinomas. Int. J. Oncol. 2016, 48, 506-516. [CrossRef]

35. Gorringe, K.L.; Cheasley, D.; Wakefield, M.J.; Ryland, G.L.; Allan, P.E.; Alsop, K.; Amarasinghe, K.C.; Ananda, S.; Bowtel, D.D.L.; Christie, M.; et al. Therapeutic Options for mucinous ovarian carcinoma. Gynecol. Oncol. 2020, 156, 552-560. [CrossRef]

36. Yang, D.; Khan, S.; Sun, Y.; Hess, K.; Shmulevich, I.; Sood, A.K.; Zhang, W. Association of BRCA1 and BRCA2 mutations with survival, chemotherapy sensitivity, and gene mutator phenotype in patients with ovarian cancer. JAMA 2011, 306, 1557-1565. [CrossRef]

37. Ledermann, J.; Harter, P.; Gourley, C.; Friedlander, M.; Vergote, I.; Rustin, G.; Scott, C.L.; Meier, W.; Shapira-Frommer, R.; Safra, T.; et al. Olaparib maintenance therapy in patients with platinum-sensitive relapsed serous ovarian cancer: A preplanned retrospective analysis of outcomes by BRCA status in a randomised phase 2 trial. Lancet Oncol. 2014, 15, 852-861. [CrossRef]

38. Patch, A.M.; Christie, E.L.; Etemadmoghadam, D.; Garsed, D.W.; George, J.; Fereday, S.; Nones, K.; Cowin, P.; Alsop, K.; Bailey, P.J.; et al. Whole-genome characterization of chemoresistant ovarian cancer. Nature 2015, 521, 489-494. [CrossRef]

39. Mendes-Pereira, A.M.; Martin, S.A.; Brough, R.; McCarthy, A.; Taylor, J.R.; Kim, J.S.; Waldman, T.; Lord, C.J.; Ashworth, A. Synthetic lethal targeting of PTEN mutant cells with PARP inhibitors. EMBO Mol. Med. 2009, 1, 315-322. [CrossRef]

40. Konecny, G.E.; Wang, C.; Hamidi, H.; Winterhoff, B.; Kalli, K.R.; Dering, J.; Ginther, C.; Chen, H.W.; Dowdy, S.; Cliby, W.; et al. Prognostic and therapeutic relevance of molecular subtypes in high-grade serous ovarian cancer. J. Natl. Cancer Inst. 2014, 106. [CrossRef]

41. Wang, Z.C.; Birkbak, N.J.; Culhane, A.C.; Drapkin, R.; Fatima, A.; Tian, R.; Schwede, M.; Alsop, K.; Daniels, K.E.; Piao, H.; et al. Profiles of genomic instability in high-grade serous ovarian cancer predict treatment outcome. Clin. Cancer. Res. 2012, 18, 5806-5815. [CrossRef] [PubMed]

42. Pennington, K.P.; Walsh, T.; Harrell, M.I.; Lee, M.K.; Pennil, C.C.; Rendi, M.H.; Thornton, A.; Norquist, B.M.; Casadei, S.; Nord, A.S.; et al. Germline and somatic mutations in homologous recombination genes predict platinum response and survival in ovarian, fallopian tube, and peritoneal carcinomas. Clin. Cancer. Res. 2014, 20, 764-775. [CrossRef]

43. Manie, E.; Popova, T.; Battistella, A.; Tarabeux, J.; Caux-Moncoutier, V.; Golmard, L.; Smith, N.K.; Mueller, C.R.; Mariani, O.; Sigal-Zafrani, B.; et al. Genomic hallmarks of homologous recombination deficiency in invasive breast carcinomas. Int. J. Cancer 2016, 138, 891-900. [CrossRef] [PubMed]

44. Popova, T.; Manie, E.; Rieunier, G.; Caux-Moncoutier, V.; Tirapo, C.; Dubois, T.; Delattre, O.; Sigal-Zafrani, B.; Bollet, M.; Longy, M.; et al. Ploidy and large-scale genomic instability consistently identify basal-like breast carcinomas with BRCA1/2 inactivation. Cancer Res. 2012, 72, 5454-5462. [CrossRef] [PubMed]

45. Liu, J.F.; Barry, W.T.; Birrer, M.; Lee, J.M.; Buckanovich, R.J.; Fleming, G.F.; Rimel, B.; Buss, M.K.; Nattam, S.; Hurteau, J.; et al. Combination cediranib and olaparib versus olaparib alone for women with recurrent platinum-sensitive ovarian cancer: A randomised phase 2 study. Lancet Oncol. 2014, 15, 1207-1214. [CrossRef]

46. Ray-Coquard, I.; Pautier, P.; Pignata, S.; Perol, D.; Gonzalez-Martin, A.; Berger, R.; Fujiwara, K.; Vergote, I.; Colombo, N.; Maenpaa, J.; et al. Olaparib plus Bevacizumab as First-Line Maintenance in Ovarian Cancer. N. Engl. J. Med. 2019, 381, 2416-2428. [CrossRef]

47. Verhaak, R.G.; Tamayo, P.; Yang, J.Y.; Hubbard, D.; Zhang, H.; Creighton, C.J.; Fereday, S.; Lawrence, M.; Carter, S.L.; Mermel, C.H.; et al. Prognostically relevant gene signatures of high-grade serous ovarian carcinoma. J. Clin. Investig. 2013, 123, 517-525. [CrossRef] 
48. Kommoss, S.; Winterhoff, B.; Oberg, A.L.; Konecny, G.E.; Wang, C.; Riska, S.M.; Fan, J.B.; Maurer, M.J.; April, C.; Shridhar, V.; et al. Bevacizumab May Differentially Improve Ovarian Cancer Outcome in Patients with Proliferative and Mesenchymal Molecular Subtypes. Clin. Cancer. Res. 2017, 23, 3794-3801. [CrossRef]

49. Topalian, S.L.; Taube, J.M.; Anders, R.A.; Pardoll, D.M. Mechanism-driven biomarkers to guide immune checkpoint blockade in cancer therapy. Nat. Rev. Cancer. 2016, 16, 275-287. [CrossRef]

50. Hamanishi, J.; Mandai, M.; Ikeda, T.; Minami, M.; Kawaguchi, A.; Murayama, T.; Kanai, M.; Mori, Y.; Matsumoto, S.; Chikuma, S.; et al. Safety and Antitumor Activity of Anti-PD-1 Antibody, Nivolumab, in Patients With Platinum-Resistant Ovarian Cancer. J. Clin. Oncol. 2015, 33, 4015-4022. [CrossRef]

51. Fujiwara, K.; McAlpine, J.N.; Lheureux, S.; Matsumura, N.; Oza, A.M. Paradigm Shift in the Management Strategy for Epithelial Ovarian Cancer. Am. Soc. Clin. Oncol. Educ. Book 2016, 35, e247-e257. [CrossRef] [PubMed]

52. Howitt, B.E.; Strickland, K.C.; Sholl, L.M.; Rodig, S.; Ritterhouse, L.L.; Chowdhury, D.; D'Andrea, A.D.; Matulonis, U.A.; Konstantinopoulos, P.A. Clear cell ovarian cancers with microsatellite instability: A unique subset of ovarian cancers with increased tumor-infiltrating lymphocytes and PD-1/PD-L1 expression. Oncoimmunology 2017, 6, e1277308. [CrossRef] [PubMed]

(C) 2020 by the authors. Licensee MDPI, Basel, Switzerland. This article is an open access article distributed under the terms and conditions of the Creative Commons Attribution (CC BY) license (http://creativecommons.org/licenses/by/4.0/). 